\title{
EVOLUCIÓN DE LA JURISPRUDENCIA ELECTORAL SOBRE LOS DERECHOS POLÍTICOS DE LAS COMUNIDADES INDÍGENAS
}

\author{
José Alejandro LUNA RAmos ${ }^{1}$
}

\section{Sumario:}

I. Introducción

II. La suplencia total de la queja y las responsabilidades de la autoridad electoral local: el caso Tanetze

III. El deber de propiciar la conciliación, y el derecho a la interpretación más favorable de las normas procesales: el caso Guelache

IV. El reconocimiento de las normas y procedimientos indígenas en materia electoral y las decisiones de la asamblea comunitaria: el caso San Jerónimo Sosola.

V. Paradigma del garantismo electoral: el caso Cherán

VI. La maximización del derecho de las asociaciones indígenas a constituirse como partidos políticos: el caso Shuta Yoma

VII. La consolidación de la línea jurisprudencial garantista del Tribunal Electoral en la defensa de los derechos de los pueblos y comunidades indígenas

VIII. Reflexiones finales

\section{I.INTRODUCCIÓN}

Los derechos fundamentales de los pueblos y comunidades indígenas, así como de sus integrantes en lo individual, constituyen palestras jurídicas orientadas a proteger estos conglomerados sociales a través de una diferenciación de trato, que redunda en una mayor igualdad entre los ciudadanos.

\footnotetext{
${ }^{1}$ Exmagistrado presidente del Tribunal Electoral del Poder Judicial de la Federación.
} 
Esta obra forma parte del acervo de la Biblioteca Jurídica Virtual del Instituto de Investigaciones Jurídicas de la UNAM

Los pueblos y comunidades indígenas se encuentran en una situación de desventaja respecto del resto de la población, dadas sus condiciones históricas de marginalidad social, pobreza y discriminación. Estas condiciones colocan a dichos sectores de la sociedad mexicana en una grave situación de vulnerabilidad, por lo cual, resulta imperioso que todas las autoridades del Estado mexicano acometan soluciones jurídicas protectivas, que busquen reducir a la mínima expresión su problemática ancestral.

La necesidad de construir criterios jurisdiccionales cobra sentido cuando se constata la relegación histórica de sus formas de vida, tradiciones, costumbres, entramados sociopolíticos que les son propios, así como el dificultoso acceso a la justicia que les aqueja. Nada de ello puede pasar desapercibido para los juzgadores llamados a resolver un litigio en el que se pongan en entredicho los derechos políticos de los pueblos y comunidades.

En lo que corresponde a la labor del Tribunal Electoral del Poder Judicial de la Federación, el contexto pluricultural del país ha sido tomado en especial consideración a la hora de hacer frente a problemáticas que involucran la efectividad de tales derechos. Como se observará con el desarrollo de esos criterios a lo largo de este trabajo, el eje vertebrador de las sentencias del Tribunal ha sido garantizar que dichos pueblos y comunidades se involucren en los asuntos públicos, y que participen en la dinámica del régimen democrático de derecho, tal como lo postula la propia Constitución mexicana. En esta tesitura, estos criterios jurisprudenciales sin temor a equivocación alguna, se manejan en estándares progresistas a favor de los derechos fundamentales de los sujetos indígenas.

La jurisprudencia electoral construida en los últimos años a favor de la tutela efectiva de los más variados derechos de estas comunidades, ha redundado en condiciones de mejora de sus niveles de vida y participación política. Asimismo, más allá de su trabajo jurisdiccional, el Tribunal Electoral ha contribuido a interiorizar estos derechos en la sociedad mexicana, implementando acciones que involucran desde programas de capacitación hasta un contacto directo con estas colectividades, mediante proyectos compartidos con las propias comunidades.

En todo caso, puede afirmarse que la jurisprudencia electoral en esta materia se ha convertido en un referente nacional e internacional, así como en un valioso acervo que enaltece la pluriculturalidad como un pilar fundamental del complejo sistema político y 
Esta obra forma parte del acervo de la Biblioteca Jurídica Virtual del Instituto de Investigaciones Jurídicas de la UNAM www.juridicas.unam.mx

democrático mexicano.

\section{II.LA SUPLENCIA TOTAL DE LA QUEJA Y LAS RESPONSABILIDADES DE LA AUTORIDAD ELECTORAL LOCAL: EL CASO TANETZE}

En primer lugar, debe hacerse referencia al juicio para la protección de los derechos político-electorales SUP-JDC-11/2007, conocido como "caso Tanetze". Puede afirmarse que con este asunto, da inicio la más reciente etapa jurisprudencial garantista en la protección de los derechos de los miembros de las comunidades indígenas en materia político-electoral. $^{2}$

El 11 de enero de 2007, veinte ciudadanos integrantes de la comunidad indígena de Tanetze de Zaragoza, estado de Oaxaca, promovieron un juicio electoral ciudadano para impugnar la determinación de las autoridades locales en el sentido de no celebrar elecciones municipales, bajo el argumento de la falta de condiciones necesarias para su realización. $^{3}$

Como es conocido, el juicio ciudadano permite la posibilidad de suplir la deficiencia en las defensas de los actores. Sin embargo, en este caso las insuficiencias de las demandas eran tan evidentes que a fin de maximizar los derechos de los miembros de la comunidad indígena de Tanetze, se resolvió que la suplencia de los agravios era todavía más amplia, en un sentido casi absoluto, a favor de los integrantes de comunidades indígenas, a efecto de facilitar su acceso efectivo a la justicia.

En efecto, se sostuvo que cuando acudan miembros de las comunidades indígenas a defender su derecho a la autodeterminación política, ante la autoridad jurisdiccional electoral, no sólo deben suplirse sus motivos de agravio sino también la ausencia total de

\footnotetext{
${ }^{2}$ Desde luego, existen importantes pronunciamientos previos a esta etapa, como es el caso Tlacolulita, en el que ya se había reconocido que las normas procesales deben interpretarse de la forma que resulte más favorable para los pueblos indígenas. Cfr. La sentencia del SUP-JDC-037/99, aprobada el 10 de febrero de 2000.

${ }^{3}$ Cfr. Luna Ramos, José Alejandro, "Los alcances de la jurisdicción en materia electoral. El caso Tanetze”, en González Oropeza, Manuel (coord.), Derecho electoral, Obra jurídica enciclopédica, México, Porrúa-Centro de Investigación e Informática Jurídica de la Escuela Libre de Derecho, 2013, pp. 379-390; Atienza, Manuel, Reflexiones sobre tres sentencias del Tribunal Electoral: casos Tanetze, García Flores y Yurécuaro, México, TEPJF, 2009, pp. 30-38.
} 
Esta obra forma parte del acervo de la Biblioteca Jurídica Virtual del Instituto de Investigaciones Jurídicas de la UNAM www.juridicas.unam.mx

los mismos. ${ }^{4}$

En esta tesitura, debe aplicarse como medida especial y compensatoria una suplencia amplia que permita al juzgador examinar, de manera oficiosa y libre, los motivos de inconformidad planteados, aun cuando existan omisiones, defectos, confusiones o limitaciones en su exposición, así como allegarse de elementos de convicción del expediente tendentes a acreditar la vulneración de los derechos político-electorales de los ciudadanos indígenas, incluso si dichos elementos no fueron siquiera ofrecidos. En este orden de ideas, se estableció que el juzgador debe acometer su juicio sin más limitación que el respeto a los principios de congruencia y de contradicción.

Estas argumentaciones se fundaron en la consideración de que los miembros de los pueblos y comunidades indígenas son personas en una situación real de desigualdad, la cual limita su acceso a la justicia, por lo que para compensar dicha circunstancia perjudicial, con un espíritu garantista, el proceso respectivo debe caracterizarse por su antiformalismo, a efecto de superar las desventajas procesales en las que se encuentran, dadas sus particulares circunstancias culturales, económicas y sociales. ${ }^{5}$

En consecuencia, el Tribunal Electoral ordenó al Consejo General del Instituto local a que dispusiera lo necesario, suficiente y razonable para que se considerara la posibilidad de realizar elecciones de concejales en el referido municipio. Esta determinación se consiguió con base en una interpretación sistemática de la legislación mexicana, de principios del derecho, instrumentos internacionales tales como la Convención Americana de Derechos Humanos y el Pacto Internacional de Derechos Civiles y Políticos, así como la jurisprudencia de la Corte Interamericana de Derechos Humanos. ${ }^{6}$

\footnotetext{
${ }^{4}$ Cfr. Vigo, Rodolfo Luis, Reflexiones iusfilosóficas de una decisión judicial. Suplencia de la queja total en los juicios electorales, México, TEPJF, 2009, pp. 45 y 46.

${ }^{5}$ En este punto, Garzón Valdés ha destacado la preocupación de la sentencia por asegurar la vigencia de la igualdad ciudadana en el ejercicio de los derechos y el cumplimiento de deberes, que es un presupuesto básico de toda democracia representativa. Cfr. Garzón Valdés, Ernesto, Los derechos electorales de los pueblos indígenas en México, TEPJF, 2010, pp. 13, 80-99.

${ }^{6}$ Este trascendental asunto fue fundacional de una sostenida línea jurisprudencial del Tribunal Electoral en las cuestiones indígenas. Entre las múltiples jurisprudencias al respecto, cabe destacar la núm. 13/2008, COMUNIDADES INDíGENAS. SUPLENCIA DE LA QUEjA EN LOS JUICIOS ELECTORALES PROMOVIDOS POR SUS INTEGRANTES, y la

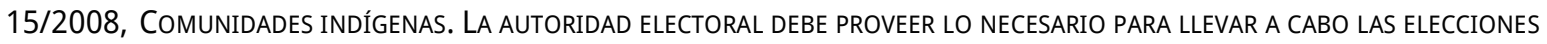


Esta obra forma parte del acervo de la Biblioteca Jurídica Virtual del Instituto de Investigaciones Jurídicas de la UNAM www.juridicas.unam.mx

Es importante subrayar que si bien, los criterios como los anteriores emanan de un proceso jurisdiccional que, en su diseño institucional, sirve para proteger los derechos político-electorales de los ciudadanos, a partir de normas de derecho positivo, el Tribunal Electoral se aproximó a estas reglas tomando en consideración que se trataba de la tutela de los derechos de proyección colectiva, de los pueblos y comunidades indígenas. Así, arribó a la conclusión de que, en este rubro, debe operar la suplencia total de la deficiencia de la queja por parte de las autoridades jurisdiccionales electorales en caso de "que se plantee el menoscabo de su autonomía política o de los derechos de sus integrantes para elegir sus autoridades o representantes, conforme a sus propias normas, procedimientos y prácticas tradicionales".

Precisamente en esa sintonía argumental, cabe resaltar que de este caso también se desprende la jurisprudencia del Tribunal Electoral, tratándose de la notificación de actos o resoluciones de la autoridad electoral por periódico oficial, el juzgador debe ponderar las situaciones particulares para tenerla por eficazmente realizada. En este tenor, los juzgadores deben atender a las costumbres y especificidades culturales de estos entes para determinar si fue eficaz la publicación del acto o resolución reclamado. En efecto, se sostuvo, las determinaciones de las autoridades electorales que deban comunicarse a los miembros de comunidades y pueblos indígenas debe hacerse en forma efectiva y conforme a las condiciones específicas de cada lugar, a fin de que se encuentren en posibilidad de adoptar una defensa adecuada de acuerdo a su esfera jurídica. ${ }^{7}$

\section{III.EL DEBER DE PROPICIAR LA CONCILIACIÓN, Y EL DERECHO A LA INTERPRETACIÓN MÁS FAVORABLE DE LAS NORMAS PROCESALES: EL CASO GUELACHE}

En el juicio ciudadano SUP-JDC-2542/2007, la Sala Superior analizó un caso en el que los agentes municipales de las poblaciones de San Gabriel Guelache, San Miguel Guelache y Asunción Guelache, en reiteradas ocasiones, instaron al Instituto Electoral de Oaxaca para obtener una cita, a efecto de participar en las elecciones de dicha municipalidad. La autoridad electoral local levantó una minuta de trabajo en la que hizo constar la

POR USOS Y COSTUMBRES (LEGISLACIÓN DE OAXACA), Gaceta de Jurisprudencia y Tesis en materia electoral, Cuarta Época, 2009, pp. 16-18.

${ }^{7}$ Cfr. Jurisprudencia 15/2010, COMUNIDADES INDÍGENAS. NOTIFICACIÓN DE ACTOS O RESOLUCIONES DE AUTORIDAD ELECTORAL POR PERIÓDICO OFICIAL, EL JUZGADOR DEBE PONDERAR LAS SITUACIONES PARTICULARES PARA TENERLA POR EFICAZMENTE REALIZADA, Gaceta de Jurisprudencia y Tesis en materia electoral, Cuarta Época, 2010, pp. 21 y 22. 
Esta obra forma parte del acervo de la Biblioteca Jurídica Virtual del Instituto de Investigaciones Jurídicas de la UNAM

imposibilidad de entablar una plática conciliatoria por falta de comparecencia del presidente municipal, sin que señalara nueva fecha, aun cuando persistía la solicitud de los referidos agentes.

La Sala Superior consideró que el Instituto Electoral local no se condujo de manera que propiciara una verdadera conciliación entre los grupos representados por las agencias municipales, con los ciudadanos de la cabecera municipal, en términos de lo establecido en el artículo 125 del Código de Instituciones Políticas y Procedimientos Electorales del Estado. Esta actuación resultaba indispensable para privilegiar la gobernabilidad democrática, a través de la evasión de conflictos posteriores entre los diversos grupos o comunidades que integraban la municipalidad. ${ }^{8}$

En consecuencia, se determinó dejar sin efecto el acuerdo del Instituto Electoral local y el decreto del Congreso oaxaqueño en los cuales se había validado la elección de concejales del municipio, y ordenar al Instituto a que dispusiera lo necesario para efectuar nuevas elecciones de concejales.

Es importante subrayar que, en este caso, también se confirmó la existencia del derecho de los sujetos indígenas a que se interpreten las normas procesales de la forma que les resulte más favorable, en los juicios de carácter electoral. Este criterio se desprendió de la interpretación funcional del artículo 20., apartado A, fracción VIII, de la Constitución, el cual reconoce a estas colectividades el derecho de acceso pleno a la jurisdicción del Estado, e impone el deber de establecer protecciones jurídicas especiales a su favor, tanto colectiva como individualmente, considerando sus condiciones en desigualdad y facilitándoles el acceso efectivo a la tutela judicial.

\footnotetext{
${ }^{8}$ El criterio que establece el deber de las autoridades electorales en el sentido de agotar pláticas de conciliación y consultas en elecciones fundadas en usos y costumbres, se aplicó también en la sentencia al SUP-JDC-2568/2007. En este asunto, la Sala Superior determinó dejar sin efectos el acuerdo del Consejo General del Instituto Electoral de Oaxaca por el cual había declarado la validez de la elección de ayuntamiento en el municipio de San Nicolás Miahuatlán, así como la del decreto núm. 7 del Congreso local, y ordenó al Instituto Electoral del Estado a que dispusiera lo necesario, suficiente y razonable a efecto de que, mediante la conciliación pertinente, consultas requeridas y resoluciones respectivas, se realizaran nuevas elecciones de concejales en dicho municipio. Asimismo, recientemente, al resolverse el expediente SUP-REC825/2014 (caso Santiago Atitlán, Oaxaca), se ratificó el criterio de que, al juzgar una elección por usos y costumbres, debe privilegiarse el consenso y la mediación entre las comunidades, y evitar el agravamiento de conflictos.
} 
Esta obra forma parte del acervo de la Biblioteca Jurídica Virtual del Instituto de Investigaciones Jurídicas de la UNAM www.juridicas.unam.mx

A partir de estas premisas, se consideró que debe evitarse colocar a las personas y comunidades indígenas en un estado de indefensión, al exigirles la satisfacción de cargas procesales irracionales o desproporcionadas, tomando en cuenta su circunstancia de desventaja social y económica. Por lo tanto, se determinó que, dado su carácter tutelar, debe establecerse que los medios de impugnación por medio de los cuales se protegen los derechos político-electorales del ciudadano se rigen por formalidades especiales para su adecuada protección. ${ }^{9}$

\section{IV.EL RECONOCIMIENTO DE LAS NORMAS Y PROCEDIMIENTOS INDÍGENAS EN MATERIA ELECTORAL Y LAS DECISIONES DE LA ASAMBLEA COMUNITARIA: EL CASO SAN JERÓNIMO SOSOLA}

Con base en el reconocimiento jurídico de las normas y procedimientos indígenas, en la sentencia recaída al recurso SUP-REC-2/2011, el Tribunal Electoral argumentó que los usos y costumbres (esto es, propiamente, el derecho electoral indígena), constituyen el marco jurídico y político mediante el cual una comunidad ejerce su autogobierno y regula sus relaciones sociales, permitiéndose de esta manera el respeto y la conservación de su cultura.

La sentencia identificó el sistema jurídico de las comunidades indígenas, integrado con las normas consuetudinarias y aquellas establecidas por el órgano de producción normativa de mayor jerarquía de la propia comunidad, que es, por regla general, su asamblea. Ello es así porque es en la asamblea comunitaria donde las decisiones que se emiten, de conformidad con el procedimiento respectivo, privilegian la voluntad de la mayoría. $^{10}$

A partir de la interpretación de la legislación electoral local, se argumentó que la voluntad mayoritaria emana precisamente de la asamblea, o con la suma de las

\footnotetext{
${ }^{9}$ En realidad, como se mencionó, este criterio fue construyéndose a partir de las consideraciones vertidas en asunto anterior, el juicio para la protección de los derechos político-electorales del ciudadano SUP-JDC037/99, resuelto el 10 de febrero de 2000 (supra nota 1), reiterándose posteriormente en la resolución al juicio SUP-JDC-2568/2007. A la postre, con estos pronunciamientos se integró la jurisprudencia 28/2011, COMUNIDADES INDÍGENAS. LAS NORMAS PROCESALES DEBEN INTERPRETARSE DE LA FORMA QUE LES RESULTE MÁS FAVORABLE, Gaceta de Jurisprudencia y Tesis en materia electoral, Quinta Época, 2011, pp. 19 y 20.

${ }^{10}$ De este caso, surgió la tesis XL/2011, ComunidAdeS INDÍGENAS. INTEGRACión DE LA ASAMBLEA GeNERAL ComUNITARIA (LEGISLACIÓN DE OAXACA), Gaceta de Jurisprudencia y Tesis en materia electoral, Quinta Época, 2011, pp. 52 y 53.
} 
Esta obra forma parte del acervo de la Biblioteca Jurídica Virtual del Instituto de Investigaciones Jurídicas de la UNAM

asambleas celebradas en cada una de las localidades. En ambos casos, la toma de decisiones se alcanza en conjunto, con lo cual se estimó que la voluntad de integrar el órgano encargado de designar a la autoridad municipal puede emitirse válidamente por la "asamblea general comunitaria" del municipio, con la participación de sus integrantes, o bien, como se ha dicho, con base en las consultas realizadas en cada una de las localidades que componen el municipio.

La importancia del caso de San Jerónimo Sosola también se refleja en el criterio relativo a la fijación de las normas que deben considerarse como componentes del sistema jurídico de las comunidades indígenas. Los usos y costumbres constituyen el marco jurídico-político a través del cual una comunidad ejerce su autogobierno, y regula sus relaciones sociales. Por tanto, el sistema jurídico indígena se integra por normas consuetudinarias pero también por aquellas otras que se establecen por el órgano de producción normativa de mayor jerarquía: su asamblea. ${ }^{11}$

Finalmente, de este caso destaca otro criterio que tiene que ver con los derechos lingüísticos de estas comunidades. La Sala Superior también determinó que a fin de garantizar el pleno acceso a la justicia de las comunidades indígenas, así como preservar y enriquecer su lengua, el juzgador al conocer de los medios de impugnación, debe valorar la necesidad de designación de un intérprete y de realizar la traducción de las actuaciones afectadas en juicio, cuando así se justifique, tomando en consideración el idioma en el que se redactó la demanda y la lengua que habla la comunidad. ${ }^{12}$

\section{PARADIGMA DEL GARANTISMO ELECTORAL: EL CASO CHERÁN}

\section{Consideraciones generales del caso}

El caso San Francisco de Cherán (SUP-JDC-9167/2011) resulta paradigmático, desde distintos puntos de vista, en la historia de la jurisprudencia garantista del Tribunal Electoral del Poder Judicial de la Federación en relación con la protección de los derechos

\footnotetext{
${ }^{11}$ Cfr. Tesis XLI/2011, Comunidades indíGenas. Normas que Integran su Sistema juRídico, Gaceta de Jurisprudencia y Tesis en materia electoral, Quinta Época, 2011, pp. 52 y 53.

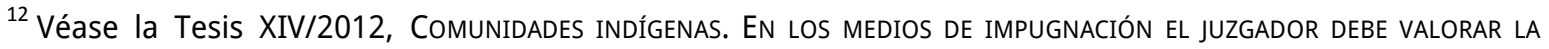
DESIGNACIÓN DE UN INTÉRPRETE Y LA REALIZACIÓN DE LA TRADUCCIÓN RESPECTIVA, Gaceta de Jurisprudencia y Tesis en materia electoral, Quinta Época, 2012, pp. 46 y 47.
} 
Esta obra forma parte del acervo de la Biblioteca Jurídica Virtual del Instituto de Investigaciones Jurídicas de la UNAM www.juridicas.unam.mx

fundamentales de los pueblos y comunidades indígenas. ${ }^{13}$

En este asunto, la población de San Francisco de Cherán solicitó elegir a sus gobernantes bajo el sistema de usos y costumbres. Aun cuando no existía una ley secundaria que regulara dicho supuesto, el Tribunal Electoral determinó que dicha circunstancia no era obstáculo para el ejercicio efectivo de sus derechos, toda vez que ello ameritaba la aplicación directa de la Constitución y de los tratados internacionales de derechos humanos invocados. ${ }^{14}$ En estas condiciones, el caso redundó en un muy representativo control de convencionalidad en materia de derechos humanos indígenas.

Los integrantes de la comunidad solicitaron al Instituto Electoral de Michoacán que realizara los actos necesarios para que sus elecciones municipales se efectuaran bajo el sistema de usos y costumbres, y no bajo el sistema de elección occidental, establecido en la Constitución local. ${ }^{15}$

${ }^{13}$ Cfr. Luna Ramos, José Alejandro, “Garantismo judicial electoral a través del control de convencionalidad: el caso Cherán", Revista del Instituto Federal de Defensoría Pública, núm. 13, junio de 2012, pp. 253-291.

${ }^{14}$ Es decir, tal como confirmó el Tribunal, dada la jerarquía de leyes establecida en el orden jurídico nacional, no era necesaria una legislación estatal para que se reconociera y protegiera un derecho humano plasmado en los tratados internacionales y, en este caso, en la Constitución federal. Así, se estimó que el estado de Michoacán vulneró la carta magna, pues su obligación era reformar sus leyes conforme a lo dictado en el artículo 20., constitucional. Por ello, el Tribunal exhortó al Congreso local a aprobar dichas reformas lo más pronto que fuera posible. Al respecto, surgió la tesis XXXVII/2011, ComUNIDADES INDíGENAS. ANTE LA AUSENCIA DE REGULACIÓN LEGAL DE SUS DERECHOS, DEBE APLICARSE LO DISPUESTO EN LA CONSTITUCIÓN Y EN LOS TRATADOS INTERNACIONALES, Gaceta de Jurisprudencia y Tesis en materia electoral, Quinta Época, 2011, pp. 50 y 51.

${ }^{15}$ A partir de estas consideraciones emanó la tesis XLII/2011, Usos Y COSTUMBRES. A LA AUTORIDAD ADMINISTRATIVA ELECTORAL CORRESPONDE CONSULTAR A LA COMUNIDAD, SI OPTA POR CELEBRAR ELECCIONES BAJO ESE RÉGIMEN Y SOMETER EL RESULTADO AL CONGRESO DEL ESTADO, Gaceta de Jurisprudencia y Tesis en materia electoral, Quinta Época, 2011, pp. 72 y 73. De conformidad con esta tesis, las comunidades indígenas tienen derecho a elegir a sus autoridades, de conformidad con sus normas, procedimientos y prácticas tradicionales. En este sentido, a falta de desarrollo legislativo, la autoridad administrativa electoral debió realizar las consultas respectivas a la comunidad para determinar si la mayoría de sus integrantes optaba por celebrar elecciones por el sistema de usos y costumbres, cuyo resultado debía someterse al Congreso del Estado a fin de que emitiera el decreto que conforme a derecho correspondiera. A este respecto, dichas consultas deben: a) surgir de la colectividad indígena y del consentimiento libre de sus integrantes; b) respetar los derechos humanos y aplicar el criterio de mayoría: c) ser democráticas y equitativas, a fin de que participe el mayor número de integrantes de la comunidad; d) responder a las necesidades identificadas por los propios pueblos; e) practicarse en forma pacífica; f) proporcionar en forma recíproca todos los datos y la información necesaria, 
Esta obra forma parte del acervo de la Biblioteca Jurídica Virtual del Instituto de Investigaciones Jurídicas de la UNAM www.juridicas.unam.mx

El Instituto Electoral local determinó que carecía de competencia para conocer el caso y, por lo tanto, no dio entrada a la petición de los integrantes de la comunidad indígena, argumentando que no existía una regulación legal aplicable. En contra de esa determinación, los solicitantes interpusieron un juicio ciudadano arguyendo que había existido conculcación a diversas disposiciones de la Constitución federal, de la Constitución local, así como de instrumentos internacionales.

La Sala Superior determinó revocar el acuerdo impugnado, otorgando la razón a los actores, y ordenó al Instituto Electoral local a que instrumentara todas las medidas administrativas necesarias, suficientes y que resultaran razonables para que se resolviera en definitiva la petición de los ciudadanos indígenas y, con ello, quedaran garantizados sus derechos fundamentales.

Cabe indicar que, con base en esta resolución, y mediante decreto número 442 de 2011, el Congreso del Estado de Michoacán determinó se llevara a cabo la elección de autoridades municipales de Cherán con el sistema de usos y costumbres, como ocurrió, en efecto, el domingo 22 de enero de 2012.

\section{Derechos de acceso a la justicia y a la autoadscripción de los miembros} de una comunidad indígena

Respecto al derecho de acceso a la justicia, se reconoció que en los casos donde sean parte las colectividades indígenas, el órgano judicial competente, al resolver la controversia, tiene el deber de interpretar las disposiciones que rigen el proceso con especial consideración de las normas consuetudinarias indígenas del caso y de las particulares condiciones o cualidades culturales del pueblo o comunidad de que se trate.

Las referidas normas comprenden los modos de vida, costumbres, conocimientos y el grado de desarrollo artístico, científico o industrial de un grupo humano socialmente cohesionado, que les identifica, y les permite autoadscribirse como miembros de ese grupo social. ${ }^{16}$

entre la comunidad y la propia autoridad, para la realización, contenidos y resultados conforme a las prácticas tradicionales, y g) las medidas adoptadas deben gestionarse por los mismos interesados.

${ }^{16}$ Fue así que del caso Cherán surgió la tesis IV/2012, ComUNIDADES INDÍGENAS. EL CRITERIO DE AUTOADSCRIPCiÓN ES SUFICIENTE PARA RECONOCER A SUS INTEGRANTES, que posteriormente se erigió en la jurisprudencia 12/2013, Gaceta de Jurisprudencia y Tesis en materia electoral, Quinta Época, 2013, pp. 25 y 26. En fechas más recientes, la Sala Superior ha reiterado este criterio, por ejemplo, en la resolución al juicio SUP-JDC-193/2012 (caso 
Esta obra forma parte del acervo de la Biblioteca Jurídica Virtual del Instituto de Investigaciones Jurídicas de la UNAM www.juridicas.unam.mx

La Sala Superior determinó que en las cuestiones indígenas el derecho a acceder "plenamente" a la jurisdicción estatal tiene un contenido normativo más amplio. La finalidad de esta perspectiva es atender, en última instancia, las condiciones fácticas en que se hallan los integrantes de los pueblos y comunidades que tradicionalmente han obstaculizado el ejercicio de sus derechos, colocándolos en una situación de discriminación jurídica. Se consideró que esto ha sido el factor que, a su vez, ha evitado que dichas poblaciones solucionen sus problemas acudiendo a los tribunales, o que lo hagan en condiciones realmente equitativas.

Se confirmó un criterio previo, mencionado con anterioridad, en el sentido de que la suplencia de la queja debe realizarse no sólo respecto a la deficiencia de los motivos de agravio sino a la ausencia total, sin más limitaciones que las derivadas por los principios de congruencia y contradicción. ${ }^{17}$

De esta manera, se cumplió con el deber de adoptar medidas positivas y compensatorias a favor de las colectividades que se hallan en esa situación de desigualdad real o material, ya que dichas medidas no se limitan a las expresamente previstas en la ley sino que es admisible el empleo de otras. ${ }^{18}$

\section{Derechos a la autonomía y a la libre determinación}

Tlaxiaco, estado de Oaxaca). A mayor abundamiento, sobre el principio de autoadscripción existe también una jurisprudencia surgida de tres asuntos previos al caso Cherán: la jurisprudencia 4/2012, COMUNIDADES INDÍGENAS. LA CONCIENCIA DE IDENTIDAD ES SUFICIENTE PARA LEGITIMAR LA PROCEDENCIA DEL JUICIO PARA LA PROTECCIÓN DE LOS DeReChos político-electorales del ciUdAdANo, Gaceta de Jurisprudencia y Tesis en materia electoral, Quinta Época, 2012, pp. 18 y 19.

${ }^{17}$ Cfr. Jurisprudencia 13/2008, supra, nota 5.

${ }^{18}$ El Tribunal Electoral encontró soporte a su decisión en el Convenio 169 de la Organización Internacional del Trabajo, sobre Pueblos Indígenas y Tribales en Países Independientes, adoptado por la Conferencia General de dicho organismo internacional el 27 de junio de 1989, ratificado por México el 5 de septiembre de 1990 y publicado en el Diario Oficial de la Federación el 24 de enero de 1991. También se apoyó en el criterio que la Corte Interamericana de Derechos Humanos relativo a los derechos de los pueblos y comunidades indígenas, conforme al cual “...de conformidad con los artículos 24 (igualdad ante la ley) y 1.1 (obligación de respetar los derechos) de la Convención Americana, los Estados deben garantizar, en condiciones de igualdad, el pleno ejercicio y goce de los derechos de las personas que están sujetas a su jurisdicción. Hay que resaltar que para garantizar efectivamente estos derechos, al interpretar y aplicar su normativa interna, los Estados deben tomar en consideración las características que diferencian a los miembros de los pueblos indígenas de la población en general y que conforman su identidad cultural"; caso Comunidad Indígena Yakye Axa vs. Paraguay, sentencia del 17 de junio de 2005, párrafo 51. 
Esta obra forma parte del acervo de la Biblioteca Jurídica Virtual del Instituto de Investigaciones Jurídicas de la UNAM

Respecto al derecho a la libre determinación y la autonomía, reconocido en el artículo 20., quinto párrafo, de la Constitución mexicana, el máximo órgano jurisdiccional electoral entendió que es la base del ejercicio de una serie de derechos específicos relacionados con los ámbitos de decisión política, económica, social y jurídica al interior de las comunidades que forman parte de los pueblos indígenas. Se estimó que ese derecho debe ser respetado por el Estado mexicano para garantizar las expresiones de identidad de dichos pueblos y de sus integrantes.

En sus consideraciones, la Sala Superior refirió lo que el Comité de Derechos Humanos de la Organización de las Naciones Unidas ha tenido en cuenta para aplicar el artículo 10. del Pacto Internacional de Derechos Civiles y Políticos, a los pueblos indígenas. ${ }^{19}$ El derecho de la autodeterminación de los pueblos indígenas se explica en la razón de que es indispensable para la preservación de sus culturas, las cuales constituyen un componente esencial de un Estado que, como el mexicano, se declara e identifica a sí mismo, y frente a la comunidad internacional, como una nación con una composición pluricultural.

En efecto, la personalidad distintiva de los pueblos indígenas no es cuestión sólo de su lengua y otras expresiones culturales, sino el resultado de la reproducción social permanente del grupo a través del funcionamiento de sus propias instituciones sociales y políticas. De ahí que, generalmente, el mantenimiento de la identidad étnica se encuentre estrechamente vinculada con el funcionamiento de esas instituciones.

Esta situación social representa un doble desafío para dichos pueblos. En primer término, conseguir un reconocimiento que combine medidas que les permitan un lugar de participación activa dentro del Estado. En segundo término, establecer una serie de medidas compensatorias para impulsar su viabilidad, dotando a los pueblos indígenas de las condiciones materiales y jurídicas necesarias, a efecto de mantenerse como pueblos y desarrollarse desde un proyecto propio, en el marco del Estado nacional.

La Sala Superior consideró que el derecho a la libre determinación comprende cuatro elementos: autoafirmación, autodefinición o autoadscripción, autodelimitación y

\footnotetext{
${ }^{19}$ Tal como se advierte en los párrafos 7 y 8 de la determinación CCPR/C/79/Add.105 del 7 abril de 1999: “observaciones finales del Comité de Derechos Humanos: Canadá”, en la cual dicho Comité afirmó que el derecho a la autodeterminación protege a los pueblos indígenas, inter alia, en el disfrute de sus derechos sobre las tierras tradicionales.
} 
Esta obra forma parte del acervo de la Biblioteca Jurídica Virtual del Instituto de Investigaciones Jurídicas de la UNAM

autodisposición. El derecho de autoafirmación otorga a los pueblos indígenas la capacidad exclusiva de proclamarse existente, mientras el de autodefinición determina por sí mismo quiénes son las personas que lo constituyen. El derecho a la autoadscripción permite a los sujetos, en lo particular, identificarse como miembros de dichos pueblos; el de autolimitación le posibilita determinar por sí mismo las demarcaciones de su territorio, mientras que el de autodisposición consiste en la posibilidad de organizarse de la manera que más resulte por conveniente en el ámbito político, social, económico y cultural. ${ }^{20}$

Bajo esa perspectiva, el Tribunal Electoral determinó que el derecho de los pueblos y comunidades indígenas a la libre determinación constituye el principio que articula y engloba una serie de derechos específicos, que constituyen manifestaciones concretas de la autonomía, como son: a) autonomía para decidir sus formas internas de convivencia y organización social, económica, política y cultural; b) autonomía para aplicar sus propios sistemas normativos en la regulación y solución de sus conflictos internos, sujetándose a los principios generales de la Constitución, respetando los derechos humanos $\mathrm{y}$, especialmente, la dignidad e integridad de las mujeres; c) autonomía para elegir a las autoridades o representantes para el ejercicio de sus formas propias de gobierno interno, siguiendo para ello sus normas, procedimientos y prácticas tradicionales, en el entendido de que debe garantizarse la participación de las mujeres en condiciones de equidad frente a los varones, y d) autonomía para acceder plenamente a la jurisdicción del Estado, por lo que debe garantizarse en todos los juicios y procedimientos en los que sean parte, individual o colectivamente, que se tomen en cuenta sus costumbres y especificidades culturales, respetándose los preceptos constitucionales.

En este sentido, el derecho a elegir a las autoridades o representantes para el ejercicio de sus formas propias de gobierno interno tiene como propósito explícito el de fortalecer la participación y representación política de estos grupos étnicos.

\section{Principios pro persona, de universalidad, interdependendencia, indivisibilidad y progresividad}

La Constitución obliga a realizar una interpretación pro persona de los derechos

\footnotetext{
${ }^{20}$ Cfr. Obieta Chalbaud, José A. de, El derecho humano de la autodeterminación de los pueblos, Madrid, Tecnos, 1993, pp. 63-101.
} 
Esta obra forma parte del acervo de la Biblioteca Jurídica Virtual del Instituto de Investigaciones Jurídicas de la UNAM

humanos. Ello trae como consecuencia, entre otras cuestiones, interpretar con criterio extensivo los derechos, a efecto de potenciar su ejercicio, buscando la protección más amplia. El Tribunal entendió que el derecho al autogobierno engloba todas las manifestaciones concretas y medidas específicas a las que se ha hecho referencia, las cuales implican, el derecho a elegir a sus autoridades, su forma de organización, así como el derecho a la consulta de todas aquellas medidas de las autoridades estatales que les afecten. ${ }^{21}$

Esta interpretación implica también el derecho de las comunidades indígenas a determinar, en cualquier momento, si las elecciones de sus autoridades deben realizarse por el sistema legal ordinario, o bien, mediante sus usos y costumbres. Sobre este punto debe considerarse que la manifestación esencial de ese derecho lo constituye, precisamente, la posibilidad de decidir la forma de organización para atender sus asuntos internos y locales. Esto es así porque el principio de universalidad implica que los derechos indígenas son exigibles en cualquier contexto político, jurídico, social, y cultural, así como en cualquier momento y lugar, de tal forma que su reconocimiento o cumplimiento por las autoridades no queda a su arbitrio.

También se observaron los principios de interdependencia e indivisibilidad, porque como se ha visto, el derecho al autogobierno constituye una vertiente del derecho a la libre determinación de los pueblos indígenas, el cual articula y engloba todas las manifestaciones concretas de autonomía de dichos pueblos. El derecho al autogobierno forma parte de dicho entramado y constituye una pieza esencial para el ejercicio de la autodeterminación de tal comunidad y un elemento fundamental para el respeto y defensa de los restantes derechos de sus integrantes.

Con ello, se atiende a un principio de progresividad, en virtud de que a lo largo de los dos últimas décadas, se han realizado avances importantes en el reconocimiento de los derechos de los pueblos indígenas tanto a nivel nacional como internacional y que en nuestro país, se articularon los derechos a la libre determinación de los pueblos indígenas, y, como una de las concretas manifestaciones de la autonomía: el autogobierno.

Lo anterior resulta relevante, porque es insuficiente que la Constitución y los

\footnotetext{
${ }^{21}$ Cfr. Tesis XXXV/2013, Comunidades indíGenas. Elementos Que Componen el derecho de AUtogobierno, Gaceta de Jurisprudencia y Tesis en materia electoral, Quinta Época, 2013, pp. 91 y 92.
} 
Esta obra forma parte del acervo de la Biblioteca Jurídica Virtual del Instituto de Investigaciones Jurídicas de la UNAM

instrumentos internacionales en materia de derechos humanos de los que México es parte establezcan un conjunto de derechos por medio de los cuales se afirme el reconocimiento del derecho a la diversidad étnico-cultural de los pueblos indígenas. Es preciso que, en la práctica, las autoridades en el ejercicio del poder público, los respeten $\mathrm{y}$, ante cualquier conculcación, se garanticen también las vías para hacer factible este derecho. De lo contrario, el derecho constitucional fundamental a la debida protección de la diversidad étnico-cultural de los pueblos indígenas correría el grave riesgo de verse convertido en letra muerta.

Esos derechos, al formar parte de la Constitución y del orden jurídico nacional, deben ser aplicados por las autoridades de todos los niveles sin necesidad de que para ello exista una ley secundaria. Si la Constitución o las leyes establecen un derecho, pero la ley no establece un proceso para su protección, esta circunstancia no implica impedir su ejercicio, ni mucho menos faculta a la autoridad a vulnerarlos, sino que esta omisión obliga a instaurar un proceso encaminado a proteger el derecho, en el cual se respeten las formalidades esenciales del procedimiento.

\section{Efectos de la sentencia: características del derecho a la consulta}

a los pueblos y comunidades indígenas

La Sala Superior revocó el acuerdo emitido por el Instituto Electoral de Michoacán que había respondido negativamente a la petición de la comunidad indígena de Cherán, en el sentido de celebrar elecciones bajo sus usos y costumbres. En los efectos de la sentencia se ordenó a dicho Instituto realizar una consulta en la población para revisar si existían condiciones para organizar comicios por usos y costumbres en el municipio de Cherán. También, el Tribunal dispuso que, en la realización de las consultas y la adopción de las medidas correspondientes, se atendieran los principios establecidos tanto en el Convenio 169 de la Organización Internacional del Trabajo sobre Pueblos Indígenas y Tribales en Países Independientes, como en la Declaración sobre los Derechos de los Pueblos Indígenas de la ONU.

Se determinó que de conformidad con esos instrumentos internacionales, las consultas a los pueblos indígenas en las cuestiones que les afectan, deben realizarse con observancia en los principios siguientes: a) endógeno: el resultado de dichas consultas debe surgir de los propios pueblos y comunidades indígenas para hacer frente a necesidades de la colectividad; b) libre: el desarrollo de la consulta debe realizarse con el 
Esta obra forma parte del acervo de la Biblioteca Jurídica Virtual del Instituto de Investigaciones Jurídicas de la UNAM

consentimiento libre e informado de los pueblos y comunidades indígenas, quienes deben participar en todas las fases del desarrollo; c) pacífico: deberán privilegiarse las medidas conducentes y adecuadas, para que se establezcan todas las condiciones de diálogo y consenso que sean necesarias para evitar la generación de violencia o la comisión de cualquier tipo de desorden social al seno de la comunidad.

Asimismo, se estableció que deben ser: d) informado: es necesario proporcionar a los pueblos y comunidades indígenas todos los datos y la información necesaria respecto de la realización, contenidos y resultados de la consulta, a efecto de que puedan adoptar la mejor decisión. A su vez, dichos pueblos y comunidades deben facilitar a la autoridad la información relativa a los usos, costumbres y prácticas tradicionales, para que en un ejercicio constante de retroalimentación se lleve a cabo la consulta correspondiente; e) democrático: en la consulta se deben establecer los mecanismos correspondientes a efecto de que puedan participar el mayor número de integrantes de la comunidad, que en la adopción de las resoluciones se aplique el criterio de mayoría y se respeten en todo momento los derechos humanos; f) equitativo: debe beneficiar por igual a todos los miembros, sin discriminación, y contribuir a reducir desigualdades, garantizando la participación de las mujeres en condiciones de equidad frente a los varones; g) socialmente responsable: debe responder a las necesidades identificadas por los propios pueblos y comunidades indígenas, y reforzar sus propias iniciativas de desarrollo; debe promover el empoderamiento de los pueblos indígenas y especialmente de las mujeres indígenas, y h) autogestionado: las medidas que se adopten a partir de la consulta deben ser manejadas por los interesados a través de formas propias de organización y participación. $^{22}$

La definición de estos extremos de la consulta obedeció a que en la legislación nacional no existe regulación sobre consultas indígenas, por lo cual, al existir normatividad internacional vigente y obligatoria al respecto, en un ejercicio emblemático de control de convencionalidad, se recurrió a los referidos instrumentos internacionales para hacer efectivo ese derecho.

\section{LA MAXIMIZACIÓN DEL DERECHO DE LAS ASOCIACIONES INDÍGENAS A CONSTITUIRSE COMO PARTIDOS POLÍTICOS: EL CASO SHUTA YOMA}

\footnotetext{
${ }^{22}$ Véase el considerando noveno de la resolución al caso SUP-JDC 9167/2011.
} 
Esta obra forma parte del acervo de la Biblioteca Jurídica Virtual del Instituto de Investigaciones Jurídicas de la UNAM www.juridicas.unam.mx

En la línea jurisprudencial garantista del Tribunal Electoral que viene desarrollándose, debe hacerse referencia al juicio ciudadano SUP-JDC-1895/2012. En este asunto, la asociación civil Shuta Yoma, conformada por miembros de comunidades indígenas de Oaxaca, solicitó que se reconociera su derecho a participar como partido político en procesos comiciales.

La Sala Superior consideró que la vista por un plazo de veinticuatro horas que se había fijado a la asociación "Shuta Yoma A.C.", con un documento que superaba las dos mil hojas, a efecto de que manifestara lo que a su derecho conviniera, transgredió el derecho de previa audiencia. ${ }^{23}$ Estimó que, dada la condición indígena de los solicitantes, éstos se encontraban en una situación de vulnerabilidad que dificultaba el estudio de los resultados de la verificación, la adopción de medidas tendentes a superar las inconsistencias de su padrón de afiliados, y, finalmente, la satisfacción del mínimo de afiliados requerido por la ley.

En tales circunstancias, se recordó que era obligación de las autoridades, en el ámbito de sus competencias, interpretar los derechos humanos de la manera más favorable a los solicitantes, y que, en el caso, la calidad de indígenas de éstos constituía una condición extraordinaria que debía ser tutelada en el sentido de maximizar su derecho de asociación y participación política.

En este contexto, cuando los integrantes de comunidades indígenas solicitan el registro de un partido político, las autoridades electorales deben interpretar las disposiciones aplicables a los procedimientos de registro y constitución del mismo, de la forma más favorable, adoptando incluso las medidas compensatorias y adecuadas que maximicen la inclusión y el acceso al sistema democrático.

\footnotetext{
${ }^{23}$ El criterio relativo a que debe observarse el derecho de audiencia cuando se analiza la validez de una elección celebrada por el sistema de usos y costumbres, fue reiterado en la sentencia al expediente SUP-JDC891/2013. En este caso se determinó que el Tribunal Electoral del Estado de Guerrero debió tomar en cuenta que dicho derecho se traducía en una garantía de seguridad jurídica para los gobernados. Esta garantía imponía la ineludible obligación de las autoridades para que, de manera previa al dictado de un acto de privación, fueran cumplidas las formalidades esenciales necesarias para oír en defensa a los afectados. Así, en el caso se estimó que el Tribunal Electoral local se encontraba constreñido a llamar a juicio a todo aquel que pudiera verse afectado con motivo de la determinación que adoptaría en torno a la validez de la elección, sobre todo a aquellos que podrían resultar directamente afectados, de conformidad con el derecho fundamental a la tutela jurisdiccional efectiva, prevista en el artículo 17 constitucional.
} 
Esta obra forma parte del acervo de la Biblioteca Jurídica Virtual del Instituto de Investigaciones Jurídicas de la UNAM www.juridicas.unam.mx

A partir de estas argumentaciones, la Sala Superior emitió la tesis XXXI/2012, COMUNIDADES INDÍGENAS. DEBE MAXIMIZARSE EL DERECHO DE ASOCIACIÓN EN EL PROCEDIMIENTO DE REGISTRO DE PARTIDOS POLÍTICOS. ${ }^{24}$

Asimismo, es de destacarse que en esta sentencia se hizo especial énfasis en la condición presencial de dos sistemas electorales en el estado de Oaxaca: el de usos y costumbres, y el de partidos políticos, cuya relación no resulta ser de incompatibilidad y exclusión sino de coexistencia. En todo caso, tanto en un sistema como en el otro, cobran aplicación las disposiciones y medidas tendentes a la protección de las comunidades indígenas.

\section{VII.LA CONSOLIDACIÓN DE LA LÍNEA JURISPRUDENCIAL GARANTISTA DEL TRIBUNAL ELECTORAL EN LA DEFENSA DE LOS DERECHOS DE LOS PUEBLOS Y COMUNIDADES INDÍGENAS}

Mediante un análisis general de las resoluciones recaídas a los múltiples asuntos de los que ha conocido la Sala Superior en esta materia, es posible constatar en nuestros días una clara e irreversible consolidación de criterios antiformalistas y garantistas de los derechos políticos de los pueblos y de los ciudadanos indígenas.

A partir de dichos criterios, el Tribunal Electoral ha continuado un desarrollo jurisprudencial consecuente con este talante protector, ya sea maximizando los derechos, o construyendo nuevas vertientes de éstos, a la luz de condiciones fácticas distintas que se le han presentado a su conocimiento. A continuación se destacan algunas resoluciones más recientes que muestran esa evolución.

1. Casos San Bartolo Coyotepec y Santo Domingo Nuxaá: la equidad de género en el derecho electoral indígena

En marzo de 2014 al resolver el recurso SUP-REC-16/2014, la Sala Superior emitió otra resolución histórica; en el caso, ésta estimó que dentro del proceso comicial no fueron observados los principios de universalidad y equidad previstos en la Constitución, así como en tratados internacionales, además de que no fue hecho efectivo el derecho de las mujeres a votar y ser votadas en el proceso electivo. En el caso se advirtió que en una primera elección resultaron electos diez varones, lo cual impidió a mujeres a postularse

\footnotetext{
${ }^{24}$ Gaceta de Jurisprudencia y Tesis en materia electoral, Quinta Época, Tribunal Electoral del Poder Judicial de la Federación, año 5, núm. 11, 2012, pp. 35 y 36.
} 
Esta obra forma parte del acervo de la Biblioteca Jurídica Virtual del Instituto de Investigaciones Jurídicas de la UNAM

como candidatas. En una segunda vuelta, se limitó a las mujeres a ocupar el cargo de tercer concejal, dejándose firmes el de presidente y síndico.

Consecuentemente, la Sala Superior determinó la anulación de la elección al no haberse apegado a los principios de equidad de género, y al vulnerarse de esta manera el derecho de las mujeres a participar en la elección de los integrantes del ayuntamiento. Conculcación que trascendió a todos los actos realizados en esa asamblea, sin que se hubiera apreciado la posibilidad de seccionar dicha elección.

Por lo tanto, se declaró la nulidad de la elección de los integrantes del ayuntamiento de San Bartolo Coyotepec, Oaxaca; como consecuencia se instruyó al Instituto Electoral y de Participación Ciudadana de Oaxaca a realizar comicios extraordinarios, en los que las mujeres pudieran aspirar a todos los cargos de elección popular.

Además, se vinculó al referido Instituto para que informara, a quienes integran esa comunidad, respecto de los derechos a votar y ser votadas de los que son titulares las mujeres, a fin de propiciar condiciones de igualdad sustantiva en el desarrollo de los comicios para la designación de concejales.

No menos importante resulta destacar la sentencia recaída al recurso de reconsideración SUP-REC-438/2014, resuelto por la Sala Superior en mayo de 2014. En este caso de particular importancia para la igualdad de género en el seno del derecho electoral indígena, se demostró que, en una asamblea general comunitaria, se eligieron a los ciudadanos que integrarían el ayuntamiento de Santo Domingo Nuxaá, Oaxaca, con base en una norma consuetudinaria que restringió el derecho de votar y de ser votadas a las mujeres.

Esta situación se reflejaba en la circunstancia de que en la aludida asamblea sólo participó una mujer, igualmente se advirtió que, en general, a las mujeres de la comunidad indígena se les impidió participar en la elección de concejales del ayuntamiento. Estos actos fueron considerados por la Sala Superior como constitutivos de una clara violación al principio constitucional de participación de las mujeres en condiciones de igualdad en las elecciones celebradas bajo el sistema normativo interno indígena.

Asimismo, se argumentó que los sistemas normativos indígenas que reduzcan la participación de las mujeres a la mera validación de decisiones previamente tomadas, como ocurrió en el caso, es una práctica discriminatoria. Los derechos de las mujeres en 
Esta obra forma parte del acervo de la Biblioteca Jurídica Virtual del Instituto de Investigaciones Jurídicas de la UNAM

la vida política implican que participen activamente, permitiéndoles integrar las autoridades, así como discutir, presentar propuestas, proponer candidatos, entre otras maneras de participación.

La existencia de costumbres y prácticas que, lejos de permitir o facilitar la inclusión de los géneros en condiciones de igualdad, perpetúan una situación en la que a las mujeres no se les permite participar de modo activo en la vida política de la comunidad, hace imposible considerar la actualización del principio de universalidad del sufragio así como de la participación política de hombres y mujeres en igualdad de condiciones.

Consecuentemente, ante el impedimento de la participación de las mujeres en condiciones de igualdad en la elección referida, celebrada bajo el sistema normativo ancestral indígena, se determinó la nulidad de la elección de integrantes del ayuntamiento en el municipio de Santo Domingo Nuxaá, Oaxaca.

\section{Caso San Juan Mixtepec, Juxtlahuaca: la flexibilización}

\section{de estándares probatorios}

En este otro caso, resuelto en abril de 2014 bajo el recurso de reconsideración SUP-REC827/2014, la Sala Superior dio un paso adelante en la aplicación antiformalista de las normas procesales a los sujetos indígenas. Determinó que la garantía de acceso a la justicia de este sector social implica la flexibilidad necesaria de las normas en la admisión y valoración de las pruebas en juicios en los que se involucren a estas personas.

Al resolver el asunto, el Tribunal Electoral tomó en consideración que era insuficiente el reconocimiento del principio de suplencia de la queja deficiente ante ausencia total de agravios; llegó a la conclusión de que para alcanzar una solución que diera respuesta a una justicia verdaderamente completa, en relación con los derechos fundamentales de los indígenas, debía confirmarse el criterio de que el derecho no puede aplicarse bajo la perspectiva de un conjunto de reglas estrictas. En efecto, se trata de un mecanismo que dar soluciones de problemas de grupos humanos en situación de vulnerabilidad.

En esta lógica, resolvió confirmar la validez de la elección de San Juan Mixtepec, estado de Oaxaca, al considerar que no existían elementos suficientes para demostrar la violación a los principios constitucionales de certeza, legalidad y universalidad del sufragio, contrariamente a lo indicado por el recurrente, quien aseguraba la existencia de una coacción del voto.

Se estimó que fue equivocada la manera en que tanto el Tribunal Electoral local como 
Esta obra forma parte del acervo de la Biblioteca Jurídica Virtual del Instituto de Investigaciones Jurídicas de la UNAM

la Sala Regional Xalapa, habían desestimado las pruebas presentadas, al pasar por alto que en los medios de impugnación promovidos por personas indígenas, la valoración de pruebas también debe impregnarse de una perspectiva intercultural, atendiendo a las particularidades de su situación concreta. Dado que en el caso se trataba de declaraciones o testimonios de diversas personas que pretendían demostrar la compra y coacción del voto, dichas pruebas debieron ser admitidas para su estudio.

En el fondo del análisis pormenorizado de dichas pruebas, se concluyó que no alcanzaban a demostrar la existencia de esas prácticas, toda vez que los indicios obtenidos resultaron insuficientes para demostrar la ilicitud de la elección. De ahí que finalmente se hayan confirmado los resultados de la elección por usos y costumbres en el ayuntamiento de San Juan Mixtepec, Juxtlahuaca, estado de Oaxaca.

\section{Caso Mazatlán Villa de Flores, Teotitlán de Flores Magón: derecho}

\section{a la autodisposición normativa y al pleno e informado}

conocimiento de las resoluciones en lengua indígena

Finalmente, en su sesión del 21 de mayo de 2014, la Sala Superior resolvió los recursos de reconsideración SUP-REC-836/2014 y sus acumulados, en los cuales consideró vulnerado el derecho de las comunidades indígenas involucradas a elegir sus autoridades bajo sus normas tradicionales.

En el caso, la convocatoria para la asamblea fue emitida por una autoridad distinta a la competente; el Consejo Municipal Electoral se integró de forma diferente a lo indicado por las costumbres de dichas comunidades; la fecha y el lugar de la asamblea se fijó hasta en tres ocasiones sin consulta a la Asamblea General Mazateca; se negó la participación del Consejo de Ancianos, y varias mesas de debate fueron presididas por funcionarios del Instituto Estatal Electoral, el cual carecía de competencia.

La autoridad electoral local lejos de respetar el derecho a la libre determinación y libre gobierno de los pueblos indígenas impidió su ejercicio, al inmiscuirse de manera directa y activa en la organización del proceso electivo. De este modo, omitió garantizar el derecho a la autodeterminación en su vertiente de autodisposición normativa, y en materia política, de la comunidad indígena, al dejar de lado los acuerdos tomados de conformidad con los sistemas normativos internos.

Conforme al derecho a la autodisposición normativa, en caso de conflictos o de ausencia de reglas consuetudinarias aplicables, deben ser los propios pueblos y 
Esta obra forma parte del acervo de la Biblioteca Jurídica Virtual del Instituto de Investigaciones Jurídicas de la UNAM

comunidades a través de sus autoridades tradicionales competentes, o de mayor jerarquía, las que emitan las reglas que se aplicarán para solucionar el conflicto o solventar la laguna normativa.

Asimismo, en el asunto resultó de particular importancia establecer el principio de maximización de la autonomía, el cual implica la salvaguarda y protección del sistema normativo interno que rige a cada pueblo o comunidad, lo cual conlleva al establecimiento tanto de sus propias formas de organización como de su regulación.

En consecuencia, la Sala Superior anuló la elección de concejales del municipio así como las constancias emitidas, y ordenó la celebración de una elección extraordinaria en la que se garantizaran los principios de certeza, legalidad, independencia, imparcialidad, objetividad, autonomía y libre determinación de los pueblos indígenas.

En este asunto, fue trascendental la fijación de criterios robustecedores de los derechos lingüísticos de los ciudadanos indígenas, en términos de los efectos de la sentencia. La Sala Superior, para garantizar el pleno conocimiento de esta resolución por parte de los integrantes del municipio, ordenó la traducción de un extracto (con las consideraciones y puntos resolutivos del fallo) a la lengua mazateca del suroeste, o la que correspondiera tomando en consideración que existen en ese lugar 11,348 ciudadanos que hablan dicha lengua indígena dentro de los cuales 2,164 lo hacen de manera exclusiva, esto es, que no hablan el idioma español.

En este tenor, aunado al grado de analfabetismo existente en el municipio referido, a efecto de garantizar el pleno e informado conocimiento de la resolución, además de la traducción de mérito, se estableció que dicha traducción debía difundirse de manera fonética, a través de los mecanismos más idóneos y conocidos en la propia comunidad, y que se utilizan comúnmente para transmitir información o mensajes que interesan a todos los integrantes de la misma. ${ }^{25}$

\section{REFLEXIONES FINALES}

\footnotetext{
${ }^{25}$ A estos efectos, el Tribunal vinculó al Instituto Nacional de Lenguas Indígenas, de conformidad con la cláusula segunda, incisos a) y e) del Convenio General de Colaboración suscrito entre el Tribunal Electoral del Poder Judicial de la Federación y dicho Instituto, el 6 de mayo de 2014. Al respecto, la doctrina ya se había pronunciado por la necesidad de construir un estándar de protección pleno y efectivo de los derechos lingüísticos de los pueblos y comunidades indígenas, como el alcanzado en esta resolución. Cfr. Mesri Hashemi-Dilmaghani, Parastoo Anita, Los derechos de los pueblos indígenas, México, TEPJF, 2009, pp. 48 y 49.
} 
Esta obra forma parte del acervo de la Biblioteca Jurídica Virtual del Instituto de Investigaciones Jurídicas de la UNAM

Para que las instituciones democráticas continúen fortaleciendo la participación política de las comunidades indígenas debe abonarse a su efectiva autonomía, al pleno respeto de su identidad colectiva y al efectivo ejercicio de sus derechos político-electorales. Así lo ha entendido el Tribunal Electoral del Poder Judicial de la Federación, como lo demuestran el conjunto de sentencias, criterios, jurisprudencias y tesis que ha emitido en los últimos años, varios de los cuales se han destacado a lo largo de este estudio.

El Tribunal Electoral se ha empeñado en contribuir de manera férrea y consistente, en lo que corresponde a su alta encomienda jurisdiccional en el Estado mexicano, con las más nobles causas del derecho electoral indígena. En esta tarea, su labor no se ha conformado con conceder la tutela que corresponde a estos derechos, conforme a las particularidades del derecho indígena. Su jurisprudencia también muestra un potencial resarcitorio de los daños ocasionados por actos de autoridad que han incidido en la violación o el menoscabo de dichos derechos, y ha buscado la reconstitución efectiva de los mismos, en cada uno de los casos que han sido sometidos a su jurisdicción.

Sin embargo, pese a todos los avances enunciados en este análisis, el reto sigue siendo la continuación del complejo proceso de integración de las comunidades indígenas a la vida política del país. Este proceso fortalece el reconocimiento de los usos y costumbres como parte fundamental del régimen constitucional y del sistema jurídico electoral del país, viabiliza su desarrollo con irrestricto respeto a la identidad de estas colectividades, y con plena observancia a la igualdad de género.

Asimismo, debe continuarse una ruta de participación activa en la expansión de las directrices jurisprudenciales hacia la labor de todos los órganos de impartición de justicia electoral en la República mexicana. Así, la perseverancia en ese andar jurisdiccional, viene de la mano del perfil pedagógico de la jurisprudencia del máximo tribunal constitucional en materia electoral.

El trabajo del Tribunal Electoral del Poder Judicial de la Federación que se avizora hacia el futuro, no palidece su responsabilidad como tribunal constitucional, tutelador de los derechos fundamentales de los pueblos y comunidades indígenas. Por el contrario, dentro de sus ejes institucionales se encuentra el reforzar su función jurisdiccional, profundizar y expandir la justicia electoral indígena, con una, cada vez más, firme vocación garantista, que permita perfeccionar, en términos reales y contundentes, las condiciones de vida de estos sectores sociales de nuestro país. 